\title{
Individuals' conceptions of COVID-19 pandemic through metaphor analysis
}

\author{
Ayşe Gök ${ }^{1}$ (i) $\cdot$ Ahmet Kara² ${ }^{2}$ (D) \\ Accepted: 16 February 2021 / Published online: 23 March 2021 \\ (C) The Author(s), under exclusive licence to Springer Science+Business Media, LLC part of Springer Nature 2021
}

\begin{abstract}
The main purpose of the current study is to investigate the perceptions of individuals' living in Turkey during the COVID-19 pandemic through metaphor analysis. The current study employed the descriptive phenomenological design, one of the qualitative research methods. A total of 210 individuals living in Turkey (114 females (68.6\%) and 66 males (31.4\%)) participated in the current study through an online questionnaire on a voluntary basis. As the data collection tool, the online questionnaire form developed by the researchers was used. The collected data were analyzed within the framework of five-stage metaphor analysis. As a result of the analysis, a total of seven metaphor categories called being restricted, restlessness, uncertainty/obscurity, deadly/ dangerous, struggling, faith/destiny, and supernatural were obtained. These categories were subsumed under three themes called "anxiety/concern, risk, and faith".
\end{abstract}

Keywords COVID-19 pandemic $\cdot$ Metaphor $\cdot$ Anxiety $\cdot$ Risk $\cdot$ Faith

\section{Introduction}

The New Coronavirus Disease (COVID-19) was first identified on January 13, 2020, as a result of the examination of a group of patients who first developed respiratory tract symptoms (fever, cough, shortness of breath) in Wuhan Province of China in late December (World Health Organization [WHO], 2020a). The pandemic was initially detected among those working in the seafood and animal market in this region. Then it spread from person to person and other cities in Hubei province, primarily Wuhan, and other provinces of the People's Republic of China and then to other countries of the world. The world has been so alarmed against this virus threat that the World Health Organization has declared it as a pandemic. In this process, individuals struggle with the psychological, sociological, and economic consequences of the pandemic (Dong \& Bouey, 2020; WHO, 2020a).

Many factors such as uncertain estimates, insufficient resources to protect healthcare providers from infection,

Ayșe Gök

ayse.gok@ohu.edu.tr

1 Department of Psychological Counselling and Guidance, Niğde Ömer Halisdemir University, 51200 Nigde, Turkey

2 Department of Psychological Counselling and Guidance, Eskisehir Osmangazi University, Eskişehir, Turkey growing financial losses, and conflicting messages from authorities can cause an increased risk of psychiatric illness associated with COVID-19 in individuals. Although medical conditions caused by natural causes such as life-threatening viral infection do not meet the trauma criteria required for Post-Traumatic Stress Disorder (PTSD) diagnosis, they have the risk of giving rise to other psychopathologies such as depression and anxiety disorders (Pfefferbaum \& North, 2020). During the fight against COVID-19, conditions such as the high risk of infection, overwork, frustration, discrimination, isolation, lack of contact with families, and fatigue, especially seen in healthcare workers, can cause mental health problems such as stress, anxiety, depressive symptoms, insomnia, denial, anger, and fear. This suggests that mental health problems will not only affect the attention, understanding, and decision-making ability of healthcare workers but also indirectly affect the fight against COVID-19. Another important issue is that this situation may have a lasting effect on the general well-being of individuals (Kang et al., 2020). On the other hand, confirmed or suspected COVID-19 patients may be afraid of the consequences of infection that can be fatal, and patients in the quarantine may experience distress, loneliness, and anger. Moreover, signs of infection such as fever and cough and negative effects of treatment such as insomnia can cause anxiety and mental distress. In any biological disaster, themes of fear, uncertainty, and stigmatization are common and they can interfere with appropriate 
mental health interventions (Xiang et al., 2020). Also, the need for mental health services or psychosocial support has increased further with the interruption of mental health services in many countries. In many countries, an increase in symptoms of depression and anxiety associated with the COVID-19 pandemic has been reported. A study in Ethiopia in April 2020 reported a 3-fold increase in the prevalence of depression symptoms compared to pre-pandemic estimates (WHO, 2020b). In another study, about one-fifth of 1577 adults reported possible anxiety and depression (Ni et al., 2020). The World Health Organization expressed its concerns about the mental health and psycho-social consequences of the COVID-19 pandemic. New measures such as selfisolation and quarantine are thought to lead to increased loneliness, anxiety, depression, insomnia, alcohol and drug use, and self-harming behaviors in humans (WHO, 2020b, 2020c). When the process of the COVID-19 pandemic is taken into consideration, it seems to be inevitable that patients, healthcare professionals, and the public are under psychological pressure that can lead to various psychological problems such as anxiety, fear, depression, and insomnia. Anxiety, loneliness, difficulty in concentrating, low motivation and distraction, hopelessness, panic, and fear, financial tension, and anxiety about the future also indicate the obvious psychological consequences of this situation (Hiremath, Kowshik, Manjunath, \& Shettar, 2020).

In the literature, there are various studies conducted on the COVID-19 pandemic. Ahorsu et al. (2020), developed the COVID-19 Fear Scale. In the study conducted by Wang et al. (2020), in China, it was found that more than half of the respondents evaluated the psychological impact of the process as moderate to severe in the first stage of the COVID-19 pandemic, and about one-third reported moderate to severe anxiety. Research findings show that this pandemic causes additional health problems such as anxiety, stress, concern, depressive symptoms, insomnia, denial, anger, and fear globally (Cao et al., 2020; Gao et al., 2020; Lie et al., 2020; Torales et al., 2020). Huang, Han, Luo, Ren \& Zhou (2020), on the other hand, found that anxiety was higher among healthcare workers during the COVID-19 pandemic. In the study conducted by Roy et al., (2020), more than $80 \%$ of the participants stated that they need mental health services during the COVID-19 pandemic. In another study, it was concluded that clinically stable COVID-19 patients suffer from significant post-traumatic stress symptoms associated with COVID19 before being discharged from the hospital (Bo et al., 2020). Satici, Gocet-Tekin, Deniz, and Satici (2020), adapted the COVID-19 Fear Scale to Turkish and investigated the relationships between COVID-19 fear and life satisfaction, depression, anxiety, and stress. In their study, Ekiz et al., (2020), evaluated the relationships between the COVID-19 pandemic control perceptions of the individuals aged 18-70 living in Turkey and their health anxiety levels.
The above-mentioned studies on the COVID-19 pandemic are generally aimed at developing scales and examining relationships between variables. On the other hand, demonstrating the perceptions, attitudes, and feelings of individuals towards this pandemic during the COVID-19 pandemic is extremely important for understanding the psychological effects of this process on individuals. At this point, metaphors which are accepted as an important way to reveal and connect abstract ideas, indirect and difficult to express feelings, attitudes, and beliefs provide the opportunity to reach deep and concrete information and findings. The Mental Metaphor Theory defines metaphor as an explanation of a mental scheme by reflecting it on another mental schema and establishing a relationship between these two schemas (Lakoff \& Johnson, 2007). In this context, it is thought that examining the process of the COVID-19 pandemic, which is an abstract and complex concept, through metaphors will create more functional and concrete cognitive patterns in understanding the meaning and importance of this process. The main purpose of the current study is to investigate the perceptions of individuals' living in Turkey during the COVID-19 pandemic through metaphor analysis. To this end, answers to the following questions were sought:

1. What are the metaphors developed by individuals living in Turkey during the pandemic about the COVID-19 pandemic?

2. Under which categories are the metaphors developed by individuals living in Turkey during the pandemic about the COVID-19 pandemic subsumed according to their common features?

3. Do the categories formed based on the metaphors developed by individuals living in Turkey during the pandemic about the COVID-19 pandemic vary significantly depending on the variables of gender, living with risky groups during the pandemic, being diagnosed with COVID-19, having any chronic disease?

\section{Methods}

\section{Design}

The current study employed the descriptive phenomenological design, one of the qualitative research approaches. In the descriptive phenomenological design, it is aimed to elicit the meanings assigned to the phenomenon by the individuals having experiences about this phenomenon and to conceptualize these meanings (Ersoy, 2016). One of these conceptualization tools is metaphors. Metaphors are known as useful and figurative forms of expression that embody the complex and abstract emotions, thoughts, expressions, and meanings of 
individuals (Collins \& Green, 1990). In the current study, the abstract and complex expressions and meanings of individuals regarding the COVID-19 pandemic are made more concrete and functional through metaphors.

\section{Procedure}

The survey was administered via Google Docs between May 10 and May 20, 2020. The participants were reached by social media platforms and personal email contacts were used to collect the data. In this way, 250 participants were reached. Later, the online questionnaire containing the weak metaphor images of 40 participants was removed from the data set. The weak metaphor can provide emotive force but provides no surplus of meaning. These are ornamental, substitutional, descriptive and trope (Tomkinson, 2009). As a result, data from 210 participants were analyzed.

\section{Sample}

A total of 210 individuals living in Turkey (114 females (\%68.6) and 66 males (\%31.4) participated in the current study through an online questionnaire on a voluntary basis [Age range $=20-69$, Mean age $=31.18$, Age sd $=10.29$ ] Demographic features of the participants are given in Table 1.

\section{Instrument}

As the data collection tool, an online questionnaire form developed by the researchers was used in the current study. There are two parts to this online questionnaire form. In the first part, there are items to elicit information about the participants' gender, age, having any chronic illness, diagnosis with COVID-19, and living with risky groups.

Table 1 Demographic features of the study group

\begin{tabular}{lllll}
\hline Variables & & & & Total \\
\hline Gender & & Female & Male & - \\
& $\mathrm{n}$ & 144 & 66 & 210 \\
& $\%$ & 68.6 & 31.4 & 100 \\
Chronic Illness & & Yes & No & - \\
& $\mathrm{n}$ & 24 & 186 & 210 \\
& $\%$ & 11.4 & 88.6 & 100 \\
COVID-19 Diagnosis & & Yes & No & - \\
& $\mathrm{n}$ & 17 & 193 & 210 \\
& $\%$ & 8.1 & 91.9 & 100 \\
Living with Risky Groups & & Yes & No & - \\
& $\mathrm{n}$ & 94 & 116 & 210 \\
& $\%$ & 44.8 & 55.2 & 100 \\
\hline
\end{tabular}

In the second part of the questionnaire form, there is the sentence "COVID-19 pandemic is like ... because ..." to be completed by the participants so that their metaphors about the COVID-19 pandemic can be elicited. In the online questionnaire form, there is a response line for the participants to present their completed sentences. The participants were asked to write their sentences in this response line. The sentences written here by the participants were used as the main data source of the study.

\section{Data Analysis}

The collected data were analyzed according to the stages of metaphor analysis proposed by Saban (2008). These stages are explained below:

\section{Coding and Eliminating}

In this stage, the metaphors produced by the participants were first alphabetically ordered. At that point, it was investigated whether the metaphors were explained clearly in the statements of the participants. To this end, coding of the metaphor produced by each participant was performed. While performing this coding operation, it was seen that metaphors were not clearly expressed in some participants' statements. Moreover, it was determined that some participants produced metaphors having characteristics belonging to more than one category. Also, some participants expressed their personal opinions rather than metaphors in their statements. "I compare it to an uncertain disease and from whom it is not known from (a sudden violent sea wave).", "A process in which irresponsible people disregard the efforts of healthcare professionals and infuriate people who are not attentive." and "Definitely, the rules must be followed until the pandemic is overcome." are examples of these thoughts. For this reason, it has been removed from the data set. As a result, the online questionnaire forms of a total of 40 participants were discarded from the dataset.

\section{Compiling}

After the exclusion of the online questionnaire forms of a total of 40 participants as they included ambiguous and poorstructured metaphors, a total of 43 valid metaphors were reached. For each metaphor, sample metaphor expressions that were thought to represent the best were included. Then, these metaphors were alphabetically ordered and the raw data were revised again. Moreover, participants' statements explaining each metaphor were re-examined. At that point, for each metaphor, a sample metaphor statement thought to best represent it was formed. Thus, a sample metaphor statement was selected for a total of 43 metaphors. In this way, it became possible to gather the metaphors under certain categories, to analyze and interpret them. 


\section{Category Formation}

In this stage, the 43 metaphors were analyzed in terms of "the source of the metaphor, the topic of the metaphor and the relationship between the source and the topic of the metaphor" and thus, they were gathered under 7 categories based on their common features. These categories are presented in Table 2.

\section{Establishing Validity and Reliability}

One of the methods used to increase validity and reliability in qualitative research is a detailed description (Creswell, 2013). In this regard, it was attempted to clearly describe the processes of inclusion of the metaphors in the study and generation of seven conceptual categories from these metaphors together with their reasons. Moreover, in qualitative research, one of the techniques used to increase reliability is the expert review (Creswell,2013). The metaphors obtained in the current study and the categories established based on these categories were subjected to the review of an academician having a doctoral degree in the field of guidance and psychological counseling and a clinic psychiatrist specialized in the field of psychology and based on the feedback given by them, they were evaluated again. Then the agreement formula proposed by Miles and Huberman (2015), for reliability analysis was used. In this process, the experts negatively evaluated 8 metaphors out of 43 valid metaphors. As a result, the reliability coefficient was found to be 0.81 . This reliability coefficient was calculated as follows:
Table 2 Categories about the COVID-19 pandemic and the metaphors included

\begin{tabular}{|c|c|c|c|}
\hline Categories & Metaphors included & $\mathrm{f}$ & $\%$ \\
\hline \multirow[t]{8}{*}{ Being restricted } & Open prison & 34 & 16.2 \\
\hline & Restricted life & 10 & 4.8 \\
\hline & Estranged family & 1 & 0.5 \\
\hline & A bird in a cage & 1 & 0.5 \\
\hline & A trapped mouse & 1 & 0.5 \\
\hline & A turtle in its shell & 1 & 0.5 \\
\hline & Spider web & 1 & 0.5 \\
\hline & Rumor parting lovers & 1 & 0.5 \\
\hline \multirow{8}{*}{ Restlessness } & Horror film & 26 & 12.4 \\
\hline & Nightmare & 7 & 3.3 \\
\hline & Depression & 5 & 2.4 \\
\hline & Trouble & 3 & 1.4 \\
\hline & Trauma & 2 & 1.0 \\
\hline & A bad dream & 1 & 0.5 \\
\hline & Nerve-racking wait & 1 & 0.5 \\
\hline & Cliff & 1 & 0.5 \\
\hline \multirow[t]{3}{*}{ Struggling } & War & 36 & 17.1 \\
\hline & A social test & 4 & 1.9 \\
\hline & An equating system & 1 & 0.5 \\
\hline \multirow[t]{7}{*}{ Uncertainty/Obscurity } & Dead well & 4 & 1.9 \\
\hline & Endless road & 7 & 3.3 \\
\hline & Dead end street & 1 & 0.5 \\
\hline & Gloomy atmosphere & 1 & 0.5 \\
\hline & Intruder & 1 & 0.5 \\
\hline & Black days & 1 & 0.5 \\
\hline & Gordian knot & 1 & 0.5 \\
\hline \multirow[t]{9}{*}{ Deadly/Dangerous } & Black Death & 10 & 4.8 \\
\hline & An invisible monster & 2 & 1.0 \\
\hline & Masked enemy & 2 & 1.0 \\
\hline & Swamp & 2 & 1.0 \\
\hline & Something insidious because you cannot see your enemy & 2 & 1.0 \\
\hline & A pressure cooker that is about to explode & 1 & 0.5 \\
\hline & An invisible bomb & 1 & 0.5 \\
\hline & A dangerous adhesive & 1 & 0.5 \\
\hline & An ever-growing complex ball & 1 & 0.5 \\
\hline \multirow[t]{4}{*}{ Supernatural } & Chaos & 9 & 4.3 \\
\hline & Disaster & 8 & 3.8 \\
\hline & Zombie invasion & 2 & 1.0 \\
\hline & A daisy opened in the middle of the desert & 1 & 0.5 \\
\hline \multirow[t]{4}{*}{ Faith/Destiny } & A sign of the apocalypse & 7 & 3.3 \\
\hline & Seclusion (Sufism) & 5 & 2.4 \\
\hline & Patience & 2 & 1.0 \\
\hline & Calamity & 1 & 0.5 \\
\hline Total & & 210 & 100 \\
\hline
\end{tabular}


Reliability $=$ Agreement $/($ Agreement + Disagreement $)$

Reliability $=35 /(35+8)=0.81$

\section{Transfer of the Data into the SPSS Program Package for Qualitative Data Analysis}

SPSS was used to analyze the descriptive statistics (frequency and percentage distributions) of themes and metaphor categories related to the Covid-19 outbreak. After the formation of a total of 43 metaphors and 7 categories, all the data were entered into the SPSS program package. Then, descriptive statistical analyses were conducted on the data and they were interpreted.

\section{Results}

In this section, first, the themes formed based on the categories related to the COVID-19 pandemic are presented. Then, the gender-based distribution of the metaphor categories and themes created by the individuals concerning the COVID-19 pandemic is given. Afterward, the distribution of the metaphor categories and themes according to living together with risky groups during the COVID-19 pandemic is discussed. Finally, the metaphor categories and themes of the individuals diagnosed with COVID-19 or having chronic illness are presented.

\section{Themes Formed Based on the Categories}

Seven metaphor categories were gathered under three themes based on their common features and similarities in meaning. These themes are; "anxiety/concern, risk, and faith". These themes and the metaphor categories they include are given in Table 3.

In Table 3, it is seen that the participants produced a total of 210 but 43 different metaphors about the COVID-19 pandemic. The frequency distribution of the themes formed based on the common features of the metaphor categories is as follows: anxiety/concern 23 (\%53.48), risk 12 (\%27.92), and faith 8 (\%18.60).

Table 3 Themes and metaphor categories related to the COVID-19 pandemic

\begin{tabular}{llll}
\hline Themes & Metaphor Categories & $\mathrm{f}$ & $\%$ \\
\hline Anxiety/Concern & Being Restricted & 8 & 18.60 \\
& Restlessness & 8 & 18.60 \\
& Uncertainty/Obscurity & 7 & 16.28 \\
Risk & Deadly/Dangerous & 9 & 20.94 \\
& Struggling & 3 & 6.98 \\
Faith & Faith/Destiny & 4 & 9.30 \\
\multirow{2}{*}{ Total } & Supernatural & 4 & 9.30 \\
\hline
\end{tabular}

Table 4 Gender-based distribution of the metaphor categories and themes about the COVID-19 pandemic

\begin{tabular}{|c|c|c|c|c|c|}
\hline \multirow[t]{2}{*}{ Gender } & \multirow[t]{2}{*}{ Metaphor groups } & \multicolumn{2}{|c|}{ Female } & \multicolumn{2}{|c|}{ Male } \\
\hline & & $\mathrm{f}$ & $\%$ & $\mathrm{f}$ & $\%$ \\
\hline \multirow[t]{8}{*}{ Categories } & Being Restricted & 33 & 22.9 & 17 & 25.8 \\
\hline & Restlessness & 38 & 26.4 & 8 & 12.1 \\
\hline & Uncertainty/Obscurity & 11 & 7.6 & 5 & 7.6 \\
\hline & Deadly/Dangerous & 15 & 10.4 & 7 & 10.6 \\
\hline & Struggling & 24 & 16.7 & 17 & 25.8 \\
\hline & Faith/Destiny & 9 & 6.3 & 6 & 9.1 \\
\hline & Supernatural & 14 & 9.7 & 6 & 9.1 \\
\hline & Total & 144 & 100 & 66 & 100 \\
\hline \multirow[t]{4}{*}{ Themes } & Anxiety/Concern & 82 & 56.9 & 30 & 45.5 \\
\hline & Risk & 39 & 27.1 & 24 & 36.4 \\
\hline & Faith & 23 & 16.0 & 12 & 18.2 \\
\hline & Total & 144 & 100 & 66 & 100 \\
\hline
\end{tabular}

As can be seen in Table 4, the most frequently produced category by the female participants during the COVID-19 pandemic is restlessness ( $\mathrm{f}=39, \% 26.4$ ), and the most frequently produced theme is anxiety/concern $(\mathrm{f}=82, \% 56.9)$ while the most frequently produced categories among the male participants are struggling $(\mathrm{f}=17, \% 25.8)$ and being restricted $(\mathrm{f}=17, \% 25.8)$ and the most frequently produced theme is anxiety/concern ( $\mathrm{f}=30, \% 45.5)$.

As can be seen in Table 5, the most frequently produced category by the participants living with risky groups during

Table 5 Distribution of the metaphor categories and themes of the participants living and not living with risky groups during the COVID19 pandemic

\begin{tabular}{llllll}
\hline $\begin{array}{l}\text { Living with } \\
\text { Risky Groups }\end{array}$ & Metaphor Groups & $\begin{array}{l}\text { Those living } \\
\text { with risky } \\
\text { groups }\end{array}$ & & $\begin{array}{l}\text { Those not living } \\
\text { with risky } \\
\text { groups }\end{array}$ \\
\cline { 3 - 4 } Categories & f & $\%$ & f & $\%$ \\
& Being Restricted & 17 & 18.1 & 33 & 28.4 \\
& Restlessness & 21 & 22.3 & 25 & 21.6 \\
& Uncertainty/Obscurity & 5 & 5.3 & 11 & 9.5 \\
& Deadly/Dangerous & 12 & 12.8 & 10 & 8.6 \\
& Struggling & 19 & 20.2 & 22 & 19.0 \\
& Faith/Destiny & 11 & 11.7 & 4 & 3.4 \\
& Supernatural & 9 & 9.6 & 11 & 9.5 \\
& Total & 94 & 100 & 116 & 100 \\
Themes & Anxiety/Concern & 43 & 45.7 & 69 & 59.5 \\
& Risk & 31 & 33 & 32 & 27.6 \\
& Faith & 20 & 21.3 & 15 & 12.9 \\
& Total & 94 & 100 & 116 & 100 \\
\hline
\end{tabular}


Table 6 Distribution of the metaphor categories and themes of the participants diagnosed with COVID-19 or having chronic illness

\begin{tabular}{|c|c|c|c|c|c|}
\hline \multirow[t]{2}{*}{$\begin{array}{l}\text { Diagnosed with COVID-19 } \\
\text { or Having Chronic Illness }\end{array}$} & \multirow[t]{2}{*}{ Metaphor Groups } & \multicolumn{2}{|c|}{$\begin{array}{l}\text { Those } \\
\text { Diagnosed } \\
\text { with } \\
\text { COVID-19 }\end{array}$} & \multicolumn{2}{|c|}{$\begin{array}{l}\text { Those } \\
\text { Having } \\
\text { Chronic } \\
\text { Disease }\end{array}$} \\
\hline & & $\mathrm{f}$ & $\%$ & $\mathrm{f}$ & $\%$ \\
\hline \multirow[t]{7}{*}{ Categories } & Being Restricted & 4 & 23.5 & 4 & 16.7 \\
\hline & Restlessness & 3 & 17.6 & 9 & 37.5 \\
\hline & Deadly/Dangerous & 6 & 35.3 & 2 & 8.3 \\
\hline & Struggling & 2 & 11.8 & 4 & 16.7 \\
\hline & Faith/Destiny & 2 & 11.8 & 1 & 4.2 \\
\hline & Supernatural & - & - & 4 & 16.7 \\
\hline & Total & 17 & 100 & 24 & 100 \\
\hline \multirow[t]{4}{*}{ Themes } & Anxiety/Concern & 7 & 41.2 & 13 & 54.2 \\
\hline & Risk & 8 & 47.1 & 6 & 25.0 \\
\hline & Faith & 2 & 11.8 & 5 & 20.8 \\
\hline & Total & 17 & 100 & 24 & 100 \\
\hline
\end{tabular}

the COVID-19 pandemic is restlessness ( $\mathrm{f}=21, \% 22.3$ ), and the most frequently produced theme is anxiety/concern ( $\mathrm{f}=$ $43, \% 45.7$ ) while the most frequently produced category by the participants not living with risky groups is being restricted $(\mathrm{f}=33,28.4 \%)$ and the most frequently produced theme is anxiety/concern ( $\mathrm{f}=69, \% 59.5)$.

As can be seen in Table 6 , the most frequently produced category by the participants diagnosed with COVID-19 during the COVID-19 pandemic is deadly/dangerous ( $\mathrm{f}=6$, \%35.3), and the most frequently produced theme is a risk ( $\mathrm{f}=8, \% 47.1$ ). Moreover, the most frequently produced category by the participants having chronic illness during the COVID-19 pandemic is restlessness ( $\mathrm{f}=9, \% 37.5$ ), and the most frequently produced theme is anxiety/concern $(\mathrm{f}=13$, $\% 54.2$ ).

\section{Discussion and Conclusion}

The purpose of the current study was to is to investigate the perceptions of individuals' living in Turkey during the COVID-19 pandemic through the metaphor analysis method. To this end, 210 participants' perceptions of the COVID-19 pandemic were analyzed with the metaphor analysis method, and thus a total of seven metaphor categories called being restricted, restlessness, uncertainty/obscurity, deadly/dangerous, struggling, faith/destiny, and supernatural were reached. These seven categories were gathered under three themes called "anxiety/concern, risk, and faith".

The participants' perceptions of the COVID-19 pandemic in the theme of Anxiety/concern were grouped under three categories called being restricted, restlessness, uncertainty/ obscurity. According to the findings showing the relationship between gender and the theme of anxiety/concern, more metaphors were produced by the female participants than the male participants in this theme. The most remarkable metaphor category produced by the female participants under the theme of anxiety/concern is restlessness, while it is the category of being restricted for the male participants. Anxiety experienced by women about a potential threat and by perceiving uncertain situations as threatening may be due to the instincts of women to ensure the safety of themselves and their offspring from an evolutionary perspective (Wood \& Eagly, 2002). This might even explain the reason for the frequent use of the "horror film" metaphor in the category of restlessness. Masculine gender roles attributed to men by society lead to behaviors such as looking strong, fearless, and assertive. Assigning the exact opposites of these behaviors to feminine gender roles may also be a reason for higher levels of anxiety in women. Similarly, the category of being restricted that is common among the male participants maybe because the aggressive and strong behaviors attributed to the male gender role were not sufficiently fulfilled during this pandemic. Also, the "open prison" metaphor, which was most frequently used by the male participants to compare with the COVID-19 pandemic, seems to be highly related to the concept of being restricted. Parallel to the finding of the current study, many other studies in the literature have found that anxiety level varies significantly depending on gender (Lewinsohn, Gotlib, Lewinsohn, Seeley, \& Allen, 1998; Schneier, Johnson, Hornig, Liebowitz, \& Weissman, 1992; Yonkers et al., 1998; Zvolensky, McNeil, Porter, \& Stewart, 2001). Similar findings have also been reported by studies focusing on the COVID-19 pandemic. It was found that being female was significantly related to the high level of anxiety associated with the COVID-19 pandemic (Ekiz et al. 2020; Huang et al. 2020; Lai et al., 2020; Wang et al., 2020; Qiu et al., 2020). In their study conducted on healthcare personnel, Zhang et al. (2020); on the other hand, found no significant difference between the male and female participants' levels of anxiety about the COVID-19 pandemic. This situation can be explained by the increase in the workload of healthcare personnel with the increasing number of cases and the fact that they are at a high risk of infection so that regardless of gender, all of them feel highly anxious. The theme of anxiety/concern was found to be the most common theme among those living with risky groups and those with chronic disease. The most obvious category of metaphor was a restlessness in those living with risky groups and the participants with chronic disease. Even though the acute or long-term consequences of the COVID-19 pandemic and accompanying social isolation on mental health are not yet clear, it may be inevitable to be concerned about the effects of a pandemic (Rubin, Potts, \& Michie, 2010). The quarantine period being longer than 
expected, negative news on social media or physical complaints caused by chronic conditions may also have caused this restlessness (Bo et al., 2020; Xiang et al., 2020). This finding of the current study is also supported by studies on pandemic diseases in the previous years (Hawryluck et al., 2004; Jeong et al., 2016; Reynolds et al., 2008; Robertson, Hershenfield, Grace, \& Stewart, 2004; Wilken et al., 2017; $\mathrm{Wu}, \mathrm{Chan}, \& \mathrm{Ma}, 2005)$. Also, the relationship between gender and themes was not analyzed quantitatively in this study. For this reason, it should be kept in mind that this situation is not a finding but only an observation.

Under the theme of risk are there the categories of deadly/ dangerous and struggling in the current study. While the frequencies of the deadly/dangerous category among the female and male participants are close to each other, the struggling category among the male participants is more common than the female participants. This can be explained by the effects of aggression, leadership, and independence attributed to the male gender role (Bem, 1975; Dökmen, 2017). In the struggling category, war is the metaphor used the most frequently to compare with the COVID-19 pandemic. In the individuals diagnosed with COVID-19, the category of deadly/dangerous was produced more than the other participants. Individuals in this group defined the COVID-19 pandemic as "an invisible monster". The fact that individuals diagnosed with COVID-19 feel more in danger than others can be explained by their struggle for life against the difficult conditions caused by the disease. Infectious disease pandemics are the situations where the psychological struggle is most difficult due to the uncertainty they cause; even more difficult than wars including armed conflicts. The restrictions brought about by these pandemics make people feel vulnerable and at risk. Having to be prepared for the unknown and uncertainty negatively affects people physically and mentally. Although the physical and emotional recovery processes are long and difficult in more typical disasters, it can be assured that the worst is over when at least the event is over, but infectious disease pandemics do not have such an open time limit. This leaves people alone with a constant source of stress which cannot be dealt with our "fight or flight" system as there is no acute stressor (State University of New York - Institute for Disaster Mental Health [SUNY-IDMH], 2020). Therefore, it can be thought that war metaphors are powerful political and emotional tools that attract the attention of individuals and are widely understood (Horton, 2020). Moreover, the statement by the United Nations Secretary-General António Guterres "Our world is facing a common enemy. We are fighting the virus." is a summary of the impact of the COVID-19 pandemic on humans.

The theme of faith is constituted by the categories of faith/ destiny and the supernatural in the current study. It was a striking detail that participants compared the COVID-19 pandemic with "a sign of the apocalypse" within the category of faith/destiny. There are various apocalyptic scenarios of religions by their theological structures. The COVID-19 pandemic may have led to a belief in the participants that the end of the world is approaching. Another explanation could be that participants think that the end of the world will be brought about by the COVID-19 pandemic. The metaphors that were included in the category of supernatural were seen to be mostly produced by the participants having a chronic illness and the most frequently used metaphors in this category are "chaos" and "disaster". When the period of the COVID-19 pandemic is considered in terms of chaos approach, this period can be thought to represent a transition phase in which the change in a system occurs unpredictably and irregularly (Duffy, 2000). When the COVID-19 pandemic is taken as a major global health crisis that continues to threaten the health and safety of the public, it may be inevitable that chaos will arise in this process. The difficulties and restrictions brought about by the COVID-19 pandemic manifest themselves in many areas. This situation can be evaluated by individuals as a harbinger of disaster. The United Nations Children's Fund (UNICEF) has announced that the COVID-19 pandemic has led to the disruption of global immune services around the world, and if the process continues, this may provide an environment for pandemics that could lead to disasters this year and beyond. Many studies on the period of the COVID-19 pandemic also addressed the chaos and disasters experienced or may be experienced in this process (Mangiarotti et al., 2020; Restubog, Ocampo, \& Wang, 2020; Tung, 2020). When the uncertainties and stressors associated with the COVID-19 pandemic are taken into consideration, all these metaphor categories can be interpreted as an expected situation. The fact that negative emotions and psychological arousal that emerge as a result of stressful experiences are disturbing for individuals motivates the person to get rid of this situation or to cope with the situation (Lazarus and Folkman, 1984). Thanks to this motivation, individuals experience the process of adapting to stress by managing their emotions in the face of stress, regulating their behavior, and trying to reduce the source of stress (Compas, Connor-Smith, Saltzman, Thomsen, \& Wadsworth, 2001). Considering that stress, trauma, and crisis are processes that are a continuation of each other (Dulmus \& Hilarski, 2003), it can be said that the stress factors resulting from the COVID-19 pandemic are important for the mental health of individuals. It has been observed that the stress that emerged as a result of infectious disease outbreaks in previous years can lead to mental health disorders (Bai et al., 2004; Lee et al., 2007; Mak et al., 2010; Maunder, 2009). On the other hand, similar findings were found in studies conducted during the COVID-19 pandemic process (Asmundson et al., 2020; Babore et al., 2020; Rogowska, Kuśnierz, \& Bokszczanin, 2020; Shechter et al., 2020; Ye et al., 2020). For this reason, it can be said that there is a need to develop stress and coping models to combat the stress related to the COVID-19 
pandemic more effectively, and some suggestions can be made in the light of the findings of the present study. In light of the findings of the current study, some suggestions can be made. First of all, in the current study, findings were obtained about which emotions individuals experienced, what cognitive patterns they developed, what attitudes and situations they were in during the pandemic of COVID-19. These findings provide an important source of information for mental health professionals. For example; in the findings of the current study, individuals diagnosed with COVID-19 or with chronic disease experience the most anxiety/concern during the pandemic. Also, the themes and categories obtained in the current study can be used in scale development studies related to COVID-19. Finally, the themes and categories obtained in the current study can be used as variables in the model development or testing studies related to COVID-19.

Data Availability Statement The datasets generated during and/or analyzed during the current study are available from the corresponding author on reasonable request.

Funding The authors received no financial support for the research, authorship, and/or publication of this article.

\section{Declarations}

All procedures performed in studies involving human participants were by the ethical standards and with the Helsinki Declaration and its later amendments or comparable ethical standards.

Informed Consent Informed consent was obtained from all individual participants included in the study.

Conflict of Interest The authors declare that they have no conflict of interest.

We have no known conflict of interest to disclose.

\section{References}

Ahorsu, D. K., Lin, C. Y., Imani, V., Saffari, M., Griffiths, M. D., \& Pakpour, A. H. (2020). The fear of covid-19 scale: development and initial validation. International Journal of Mental Health and Addiction, 1-9. https://doi.org/10.1007/s11469-020-002708

Asmundson, G. J., Paluszek, M. M., Landry, C. A., Rachor, G. S., McKay, D., \& Taylor, S. (2020). Do pre-existing anxiety-related and mood disorders differentially impact COVID-19 stress responses and coping? Journal of Anxiety Disorders, 74, 102271. https://doi.org/10.1016/j.janxdis.2020.102271

Babore, A., Lombardi, L., Viceconti, M. L., Pignataro, S., Marino, V., Crudele, M., Candelori, C., Bramanti, S. M., \& Trumello, C. (2020). Psychological effects of the COVID-2019 pandemic: Perceived stress and coping strategies among healthcare professionals. Psychiatry Research, 293, 1-6. https://doi.org/10.1016/j.psychres. 2020.113366.

Bai, Y., Lin, C. C., Lin, C. Y., Chen, J. Y., Chue, C. M., \& Chou, P. (2004). Survey of stress reactions among health care workers involved with the SARS outbreak. Psychiatric Services, 55(9), 1055-1057. https://doi.org/10.1176/appi.ps.55.9.1055.

Bem, S. L. (1975). Sex role adaptability: One consequence of psychological androgyny. Journal of Personality and Social Psychology, 31(4), 634-643 https://psycnet.apa.org/doi/10.1037/h0077098.

Bo, H. X., Li, W., Yang, Y., Wang, Y., Zhang, Q., Cheung, T., et al. (2020). Posttraumatic stress symptoms and attitude toward crisis mental health services among clinically stable patients with COVID-19 in China. Psychological Medicine, 27, 1-7. https://doi. org/10.1017/S0033291720000999

Cao, B., Wang, Y., Wen, D., Liu, W., Wang, J., Fan, G., et al. (2020). A trial of lopinavir-ritonavir in adults hospitalized with severe Covid19. New England Journal of Medicine, 382(19), 1787-1799. https:// doi.org/10.1056/NEJMoa2001282.

Collins, E. C., \& Green, J. L. (1990). Metaphors: The construction of a perspective. Theory Into Practice, 29(2), 71-77. https://doi.org/10. 1080/00405849009543435.

Compas, B., Connor-Smith, J., Saltzman, H., Thomsen, A., \& Wadsworth, M. (2001). Coping with stress during childhood and adolescence: Problems, progress, and potential in theory and research. Psychological Bulletin, 127(1), 87-127 https://psycnet.apa. org/doi/10.1037/0033-2909.127.1.87.

Creswell, J. W. (2013). Qualitative inquiry and research design: Choosing among five approaches. Sage

Dökmen, Z. Y. (2017). Social gender, social psychological explanations. Remzi Publishing House

Dong, L., \& Bouey, J. (2020). Public mental health crisis during COVID19 pandemic, China. Emerging Infectious Diseases, 26(7), 1. https:// doi.org/10.3201/eid2607.200407.

Duffy, J. A. (2000). The application of chaos theory to the careerplateaued worker. Journal of Employment Counseling, 37(4), 229 236. https://doi.org/10.1002/j.2161-1920.2000.tb01029.x.

Dulmus, C. N., \& Hilarski, C. (2003). When stress constitutes trauma and trauma constitutes crisis: The stress-trauma-crisis continuum. Brief Treatment and Crisis Intervention, 3(1), 27-36. http://triggered. edina.clockss.org/ServeContent?rft_id=info:doi/10.1093/brieftreatment $/ \mathrm{mhg} 008$.

Ekiz, T., Ilıman, E., \& Dönmez, E. (2020). Comparison of individuals' health anxiety levels with Covid-19 outbreak control perception. International Journal of Health Management and Strategies Research, 6(1), 139-154. https://dergipark.org.tr/en/pub/usaysad/ issue $/ 54067 / 729076$.

Ersoy, A. F. (2016). Phenomenology. In A. Saban \& A. Ersoy (Eds.), Qualitative research patterns in education, (pp. 51-105). An1 Publishing

Gao, J., Tian, Z., \& Yang, X. (2020). Breakthrough: Chloroquine phosphate has shown apparent efficacy in treatment of COVID-19 associated pneumonia in clinical studies. Bioscience Trends, 14(1), 72. https://doi.org/10.5582/bst.2020.01047.

Hawryluck, L., Gold, W. L., Robinson, S., Pogorski, S., Galea, S., \& Styra, R. (2004). SARS control and psychological effects of quarantine, Toronto, Canada. Emerging Infectious Diseases, 10(7), 1206-1212. https://doi.org/10.3201/eid1007.030703.

Hemenover, S. H. (2003). The good, the bad, and the healthy: Impacts of emotional disclosure of trauma on resilient self-concept and psychological distress. Society for Personality and Social Psychology, 23(10), 1236-1244. https://doi.org/10.1177/0146167203255228.

Hiremath, P., Kowshik, C. S., Manjunath, M., \& Shettar, M. (2020). COVID 19: Impact of lock-down on mental health and tips to overcome. Asian Journal of Psychiatry, 51, 1-2. https://doi.org/10.1016/ j.ajp.2020.102088.

Horton, R. (2020). Offline: COVID-19 bewilderment and candour. The Lancet, 395(10231), 1178. https://doi.org/10.1016/S0140-6736(20) 30850-3.

Huang, C., Wang, Y., Li, X., Ren, L., Zhao, J., Hu, Y., et al. (2020). Clinical features of patients infected with 2019 novel coronavirus in 
Wuhan, China. The Lancet, 395(10223), 497-506. https://doi.org/ 10.1016/S0140-6736(20)30183-5.

Jeong, H., Yim, H. W., Song, Y. J., Ki, M., Min, J. A., Cho, J., \& Chae, J. H. (2016). Mental health status of people isolated due to Middle East Respiratory Syndrome. Epidemiology and Health, 38, 1-7. https:// doi.org/10.4178/epih.e2016048

Kang, L., Li, Y., Hu, S., Chen, M., Yang, C., Yang, B. X., et al. (2020). The mental health of medical workers in Wuhan, China dealing with the 2019 novel coronavirus. The Lancet Psychiatry, 7(3), 14. https:// doi.org/10.1016/S2215-0366(20)30047-X.

Lai, J., Ma, S., Wang, Y., Cai, Z., Hu, J., Wei, N., et al. (2020). Factors associated with mental health outcomes among health care workers exposed to coronavirus disease 2019. JAMA Network Open, 3(3), 1 12. https://doi.org/10.1001/jamanetworkopen.2020.3976.

Lakoff, G., \& Johnson, M. (2007). Metaphors: Life, meaning and language (G. Y. Demir, Trans.). Paradigma

Lazarus, R. S., \& Folkman, S. (1984). Stress, appraisal, and coping. Springer Publishing Company

Lee, A. M., Wong, J. G., McAlonan, G. M., Cheung, V., Cheung, C., Sham, P. C., et al. (2007). Stress and psychological distress among SARS survivors 1 year after the outbreak. The Canadian Journal of Psychiatry, 52(4), 233-240. https://doi.org/10.1177/ 070674370705200405

Lewinsohn, P. M., Gotlib, I. H., Lewinsohn, M., Seeley, J. R., \& Allen, N. B. (1998). Gender differences in anxiety disorders and anxiety symptoms in adolescents. Journal of Abnormal Psychology, 107(1), 109-117. https://doi.org/10.1037/0021-843X.107.1.109.

Lie, S. A., Wong, S. W., Wong, L. T., Wong, T. G. L., \& Chong, S. Y. (2020). Practical considerations for performing regional anesthesia: lessons learned from the COVID-19 pandemic. Canadian Journal of Anesthesia, 67(7), 885-892. https://doi.org/10.1007/s12630-02001637-0.

Mak, I. W. C., Chu, C. M., Pan, P. C., Yiu, M. G. C., Ho, S. C., \& Chan, V. L. (2010). Risk factors for chronic post-traumatic stress disorder (PTSD) in SARS survivors. General Hospital Psychiatry, 32(6), 590-598. https://psycnet.apa.org/doi/10.1016/j.genhosppsych. 2010.07.007.

Mangiarotti, S., Peyre, M., Zhang, Y., Huc, M., Roger, F., \& Kerr, Y. (2020). Chaos theory applied to the pandemic of Covid-19: an ancillary approach to decision-making in pandemic context. Epidemiology \& Infection, 148, 1-9. https://doi.org/10.1017/ S0950268820000990

Maunder, R. G. (2009). Was SARS a mental health catastrophe? General Hospital Psychiatry, 31(4), 316-317. https://doi.org/10.1016/j. genhosppsych.2009.04.004.

Miles, M. B., \& Huberman, A. M. (2015). An expanded resource book: Qualitative data analysis. (Trans. Ed., S. Akbaba Altun, \& A. Ersoy). Pegem Academy

Ni, M. Y., Yang, L., Leung, C. M., Li, N., Yao, X. I., Wang, Y., et al. (2020). Mental health, risk factors, and social media use during the COVID-19 epidemic and cordon sanitaire among the community and health professionals in Wuhan, China. JMIR Public Health and Surveillance, 7(5), 1-6. https://doi.org/10.2196/19009.

Pfefferbaum, B., \& North, C. S. (2020). Mental health and the Covid-19 pandemic. New England Journal of Medicine, 1-3. Online ahead of print. https://www.nejm.org/doi/10.1056/NEJMp2008017

Qiu, J., Shen, B., Zhao, M., Wang, Z., Xie, B., \& Xu, Y. (2020). A nationwide survey of psychological distress among Chinese people in the COVID-19 epidemic: implications and policy recommendations. General Psychiatry, 33(2), 1-3. https://doi.org/10.1136/ gpsych-2020-100213.

Restubog, S. L. D., Ocampo, A. C. G., \& Wang, L. (2020). Taking control amidst the chaos: Emotion regulation during the COVID19 pandemic. Journal of Vocational Behavior, 119, 1-6. https://doi. org/10.1016/j.jvb.2020.103440
Reynolds, D. L., Garay, J. R., Deamond, S. L., Moran, M. K., Gold, W., \& Styra, R. (2008). Understanding, compliance and psychological impact of the SARS quarantine experience. Epidemiology \& Infection, 136(7), 997-1007. https://doi.org/10.1017/ S0950268807009156.

Robertson, E., Hershenfield, K., Grace, S. L., \& Stewart, D. E. (2004). The psychosocial effects of being quarantined following exposure to SARS: a qualitative study of Toronto health care workers. The Canadian Journal of Psychiatry, 49(6), 403-407. https://doi.org/ 10.1177/070674370404900612.

Rogowska, A. M., Kuśnierz, C., \& Bokszczanin, A. (2020). Examining anxiety, life satisfaction, general health, stress and coping styles during COVID-19 pandemic in Polish sample of university students. Psychology Research and Behavior Management, 13, 797-811. https://doi.org/10.2147/PRBM.S266511

Roy, D., Tripathy, S., Kar, S. K., Sharma, N., Verma, S. K., \& Kaushal, V. (2020). Study of knowledge, attitude, anxiety \& perceived mental healthcare need in Indian population during COVID-19 pandemic. Asian Journal of Psychiatry, 51, 102083. https://doi.org/10.1016/j. ajp.2020.102083

Rubin, G. J., Potts, H. W. W., \& Michie, S. (2010). The impact of communications about swine flu (influenza A H1N1v) on public responses to the pandemic: results from 36 national telephone surveys in the UK. Health Technology Assessment, 14(34), 183-266. https:// doi.org/10.3310/hta14340-03.

Saban, A. (2008). Metaphors about school. Educational administration: Theory and Practice, 14(3), 459-496

Satici, B., Gocet-Tekin, E., Deniz, M. E., \& Satici, S. A. (2020). Adaptation of the fear of COVID-19 Scale: Its association with psychological distress and life satisfaction in Turkey. International Journal of Mental Health and Addiction, 1-9. https://doi.org/10. 1007/s11469-020-00294-0

Schneier, F. R., Johnson, J., Hornig, C. D., Liebowitz, M. R., \& Weissman, M. M. (1992). Social phobia: Comorbidity and morbidity in an epidemiological sample. Archives of General Psychiatry, 49, 282-288. https://doi.org/10.1001/archpsyc.1992. 01820040034004

Sharma, S., Sharma, M., \& Singh, G. (2020). A chaotic and stressed environment for 2019-nCoV suspected, infected and other people in India: fear of mass destruction and causality. Asian Journal of Psychiatry, 51, 1-3. https://doi.org/10.1016/j.ajp.2020.102049

Shechter, A., Diaz, F., Moise, N., Anstey, D. E., Ye, S., Agarwal, S., et al. (2020). Psychological distress, coping behaviors, and preferences for support among New York healthcare workers during the COVID-19 pandemic. General Hospital Psychiatry, 66, 1-8. https://doi.org/10.1016/j.genhosppsych.2020.06.007

State University of New York - Institute for Disaster Mental Health (SUNY-IDMH) (2020). COVID-19: managing stress in this anxious time. Retrieved April 21, 2020, from https://www.newpaltz.edu/ media/psychology/IDMH\%20COVID 19\%20Community\% 20Stress\%20Management\%20Tip\%20Sheet\%20(1).pdf

Tomkinson, D. (2009). Thoughts on language. Retrieved February 10, 2020, from https://scholar.google.com/scholar?hl=tr\&as_sdt=0\% 2C5\&as_ylo $=2009 \&$ as_yhi $=2009 \& q=D A V E+T o m k i n s o n+\%$ $282009 \% 29 \& b \operatorname{btnG}=$

Torales, J., O'Higgins, M., Castaldelli-Maia, J. M., \& Ventriglio, A. (2020). The outbreak of COVID-19 coronavirus and its impact on global mental health. International Journal of Social Psychiatry, 66(4), 317-320. https://doi.org/10.1177/0020764020915212.

Tung, H. Y. (2020). In the matter of the virus that causes coronavirus disease (COVID-19), SARS-COV-2: A case predicted by the theory of chaos. Science Open Preprints, 1-21. https://doi.org/10.14293/ S2199-1006.1.SOR-.PPMH5LH.v1

United Nations International Children's Emergency Fund (UNICEF). (2020). Protecting the most vulnerable children from the impact of 
coronavirus: An agenda for action. Retrieved September 21, 2020, from https://www.unicef.org/coronavirus/agenda-for-action

Wang, C., Pan, R., Wan, X., Tan, Y., Xu, L., Ho, C. S., \& Ho, R. C. (2020). Immediate psychological responses and associated factors during the initial stage of the 2019 coronavirus disease (COVID-19) epidemic among the general population in China. International Journal of Environmental Research and Public Health, 17(5), 1729-1754. https://doi.org/10.3390/ijerph17051729.

Wilken, J. A., Pordell, P., Goode, B., Jarteh, R., Miller, Z., Saygar, B. G., et al. (2017). Knowledge, attitudes, and practices among members of households actively monitored or quarantined to prevent transmission of Ebola Virus Disease-Margibi County, Liberia: February-March 2015. Prehospital and Disaster Medicine, 32(6), 673-678. https://doi.org/10.1017/S1049023X17006720.

Wood, W., \& Eagly, A. H. (2002). A cross-cultural analysis of the behavior of women and men: implications for the origins of sex differences. Psychological Bulletin, 128(5), 699-727. https://doi.org/ 10.1037/0033-2909.128.5.699.

World Health Organization. (2020a). UN Policy Brief on COVID-19 and the need for action on mental health. Retrieved July 31, 2020, from https://www.who.int/emergencies/diseases/novel-coronavirus2019/events-as-they-happen

World Health Organization.(2020b). Mental health and COVID-19. Retrieved May 14, 2020, from https://www.who.int/news/item/1405-2020-substantial-investment-needed-to-avert-mental-healthcrisis

World Health Organization. (2020c). Mental health and psychosocial considerations during the COVID-19 pandemic. Retrieved March 18, 2020, from https://www.who.int/docs/default-source/ coronaviruse/mental-health-considerations.pdf
Wu, K. K., Chan, S. K., \& Ma, T. M. (2005). Posttraumatic stress after SARS. Emerging Infectious Diseases, 11(8), 1297. https://doi.org/ 10.3201/eid1108.041083.

Xiang, Y. T., Yang, Y., Li, W., Zhang, L., Zhang, Q., Cheung, T., \& Ng, C. H. (2020). Timely mental health care for the 2019 novel coronavirus pandemic is urgently needed. The Lancet Psychiatry, 7(3), 228-229. https://doi.org/10.1016/S2215-0366(20)30046-8.

Ye, Z., Yang, X., Zeng, C., Wang, Y., Shen, Z., Li, X., \& Lin, D. (2020). Resilience, social support, and coping as mediators between COVID-19-related stressful experiences and acute stress disorder among college students in China. Applied Psychology: Health and Well-Being, 12(4), 1074-1094. https://doi.org/10.1111/aphw.12211

Yonkers, K. A., Zlotnick, C., Allsworth, J., Warshaw, M., Shea, T., \& Keller, M. B. (1998). Is the course of panic disorder the same in women and men? American Journal of Psychiatry, 155(5), 596602. https://doi.org/10.1176/ajp.155.5.596.

Zhang, W. R., Wang, K., Yin, L., Zhao, W. F., Xue, Q., Peng, M., et al. (2020). Mental health and psychosocial problems of medical health workers during the COVID-19 epidemic in China. Psychotherapy and Psychosomatics, 1-9. (Epub ahead of print). https://doi.org/10. 1159/000507639

Zvolensky, M. J., McNeil, D. W., Porter, C. A., \& Stewart, S. H. (2001). Assessment of anxiety sensitivity in young American Indians and Alaska Natives. Behaviour Research and Therapy, 39(4), 477-493. https://doi.org/10.1016/S0005-7967(00)00010-3.

Publisher's Note Springer Nature remains neutral with regard to jurisdictional claims in published maps and institutional affiliations. 